\title{
Application of NIR Reflectance Spectroscopy on Rapid Determination of Moisture Content of Wood Pellets
}

\author{
Jaya Sundaram ${ }^{*}$, Sudhagar Mani ${ }^{1}$, Chari V. K. Kandala², Ronald A. Holser ${ }^{3}$ \\ ${ }^{1}$ College of Engineering, University of Georgia, Athens, USA \\ ${ }^{2}$ National Peanut Research Laboratory, Dawson, USA \\ ${ }^{3}$ Russell Research Center, Athens, USA \\ Email: "jayas@engr.uga.edu
}

Received 3 September 2015; accepted 10 November 2015; published 13 November 2015

Copyright (C) 2015 by authors and Scientific Research Publishing Inc.

This work is licensed under the Creative Commons Attribution International License (CC BY). http://creativecommons.org/licenses/by/4.0/

(c) (i) Open Access

\begin{abstract}
NIR spectroscopy was used to measure the moisture concentration of wood pellets. Pellets were conditioned to various moisture levels between $0.63 \%$ and $14.16 \%$ (wet basis) and the moisture concentration was verified using a standard oven method. Samples from various moisture levels were separated into two groups, as calibration and validation sets. NIR absorption spectral data from $400 \mathrm{~nm}$ to $2500 \mathrm{~nm}$ with $0.5 \mathrm{~nm}$ intervals were collected using pellets within the calibration and validation sample sets. Spectral wavelength ranges were taken as independent variables and the MC of the pellets as the dependent variable for the analysis. Measurements were obtained on 30 replicates within each moisture level. Partial Least Square (PLS) analysis was performed on both raw and preprocessed spectral data of calibration set to determine the best calibration model based on Standard Error of Calibration (SEC) and coefficient of multiple determinations $\left(\mathbf{R}^{2}\right)$. The PLS model that yielded the best fit was used to predict the moisture concentration of validation group pellets. Relative Percent Deviation (RPD) and Standard Error of Prediction (SEP) were calculated to validate goodness of fit of the prediction model. Baseline and Multiple Scatter Corrected (MSC) reflectance spectra with $1^{\text {st }}$ derivative model gave the highest RPD value of 4.46 and $R^{2}$ of 0.95. Also it's SEP $(0.670)$ and RMSEP $(0.782)$ were less than the other models those had RPD value more than 3.0 with less number of factors. Therefore, this model was selected as the best model for moisture content prediction of wood pellets.
\end{abstract}

\section{Keywords}

Wood Pellets, NIR Reflectance Spectroscopy, Moisture Content, Partial Least Square, Relative Percent Deviation

\footnotetext{
${ }^{*}$ Corresponding author.
}

How to cite this paper: Sundaram, J., Mani, S., Kandala, C.V.K. and Holser, R.A. (2015) Application of NIR Reflectance Spectroscopy on Rapid Determination of Moisture Content of Wood Pellets. American Journal of Analytical Chemistry, 6, 923932. http://dx.doi.org/10.4236/ajac.2015.612088 


\section{Introduction}

Wood pellets, produced from densification of sawdust or powdered wood chips are commonly used as a solid biofuels for heating and power generation applications. Among various pellet quality parameters outlined by Pellet Fuel Institute [1] (PFI, 2011), moisture content of the pellets plays a critical role in for safe handling, storage and transport of biomass and highly influences the heating content of pellets. A typical moisture content of wood pellet varies from $6 \%-10 \%(\mathrm{wb})$ [1]. Increase in moisture content of wood pellets leads to mold growth, pellet crack leading to breakage and reduced energy content of pellets. Moisture management, monitoring and control of wood pellets are important for safe storage and marketing of premium quality wood pellets. Moisture content of wood pellets is determined by conventional oven method as per the ASABE standard S358.2 [2] (ASABE, 2008). In this method, samples are usually dried at $105^{\circ} \mathrm{C}$ for $24 \mathrm{~h}$ or until no further change in weight of the sample.

Techniques using near infrared (NIR) spectroscopy for moisture concentration measurements are becoming more popular in agricultural commodities. NIR spectroscopy has several advantages over conventional physical and chemical analytical methods. It is rapid, nondestructive, and provides more information about the components and the structures present in the products. It can be used to measure more than one parameter simultaneously. NIR spectroscopy is well-suited for measurement of water, since, water O-H group overtone and combination bands are pronounced in this region of the spectrum. Water is a strong absorber in the NIR region, and samples with high water concentration are strongly dominated by the signature from water. NIR is readily adaptable and the low intensities of NIR absorptions permit the direct measurement of water over wide concentration ranges in solid samples. Spectra measured using NIR spectroscopy contain absorbance bands which are mainly due to three chemical bonds such as $\mathrm{C}-\mathrm{H}$ which is usually for fats and oil; $\mathrm{O}-\mathrm{H}$ bonds found in water; and N-H bond, which found in protein [3] (Cozzolino et al., 2008). Other chemical bonds may appear in overtone bands in NIR region. NIR spectroscopy may be applied with minimal sample preparation and has been used successfully in many agricultural crops such as peanuts [4] (Sundaram et al., 2009), soybean [5] (Nimaiyaret al., 2004), sunflower [6] (Pérez-Vich et al., 1998), rape seeds [7] (Leonardo and Becker, 1994), canola [8] (Daun et al., 1994), flax seeds [9] (Bhatty, 1991) for quality analysis. Fagan et al. [10] (2011) used NIR spectroscopy to predict the MC of ground samples of Miscanthus and SRCW. Lestander and Rhen [11] (2005) and Lestander et al., [12] (2009) used NIR spectroscopy to predict the MC of ground samples of Norway spruce with a coefficient of multiple determination of 0.99. Many of the published works on near infrared spectroscopy application for biomass and wood samples focused mainly on composition analysis [13]-[15], in which some included moisture content as a part of composition analysis; none of them solely devoted indetermination of moisture content of biomass/wood samples at various moisture levels. Therefore, the primary objective of this research is to develop calibration models to predict the MC of the wood pelletsvarying from low to high MC levels using NIR reflectance spectroscopy.

\section{Materials and Methods}

\subsection{Sample Preparation}

Wood pellets were obtained from a local pellet manufacture in Georgia, USA and stored in a plastic container in room conditions $\left(25^{\circ} \mathrm{C}\right.$ and $\left.40 \% \mathrm{RH}\right)$. The initial MC of the wood pellets was determined using the time/temperature protocol specified in the standard oven method of ASABE standard S358.2 [2]. About $100 \mathrm{~g}$ of pellet sample was placed in a small aluminum pan and this pan was kept in an air oven at $130^{\circ} \mathrm{C}$ for 6 hours. At the end of the drying time, pellet samples were removed from the oven, allowed to reach the room temperature in a desiccator and weighed. The percentage MC of the pellet sample was calculated from the weight of the sample before and after drying, and expressed as percentage MC on wet weight basis (w.b).

The initial MC of pellets was about $0.63 \%$. These pellet lots were divided into 12 sub-lots and each was placed in a separate vapor sealed air tight plastic container. Appropriate quantities of water were added to each container, to raise the moisture levels in steps of $2 \%-3 \%$ increments in the MC of the pellets. The containers were sealed and allowed to equilibrate at room temperature $21^{\circ} \mathrm{C}-23^{\circ} \mathrm{C}$ for $2-3$ days. The containers were periodically rotated during this period to allow uniform moisture distribution. This resulted in 12 moisture levels for pellets. Final moistures ranged from $0.63 \%$ to $14.16 \%$. The final MC of each sub-lot after the equilibration was measured using oven method described above, for three $100 \mathrm{~g}$ subsamples from each sub-lot. The average 
of the three replicates was taken as the MC of each sub-lot (reference value) and each sub-lot was labeled accordingly. At the end of the equilibration period NIR spectroscopy measurements were taken.

\subsection{NIR Spectroscopy Measurements}

The pellet samples, after conditioning, were separated into calibration and validation groups (Table 1). NIR spectral measurements were made using a scanning monochromator (Model 6500, FOSS NIRSystems, Silver Springs, MD, USA). Spectral data were collected using Vision software (Version 1.0, FOSS NIRSystems, Silver Springs, MD, USA). The calibration groups of pellet had 7 different moisture levels and the validation groups of pellets had 5 different moisture levels. Thirty replicates of each moisture level in each pellets groups were scannedwith 32 scan per sample. Each replicate sample consisted of $100 \mathrm{~g}$ - $200 \mathrm{~g}$ of pellet depending on the amount required to adequately fill the sample holder. The room temperature during the measurements varied from $21^{\circ} \mathrm{C}$ to $23^{\circ} \mathrm{C}$. NIR light was allowed to fall on the bottom of the sample holder containing the pellets, where it penetrated and interacted with the samples. The reflected energy was measured over the wavelength range of $400 \mathrm{~nm}$ to $2500 \mathrm{~nm}$. This reflected light spectrum that carried absorption information was collected.

\subsection{Data Analysis}

NIR spectral data were analyzed using multivariate data analysis software (Unscrambler Version 9.8 CAMO ASA, USA). Absorption values of the Spectra between $400 \mathrm{~nm}-2500 \mathrm{~nm}$ with $0.5 \mathrm{~nm}$ intervals were taken as independent variables and the MC of the pellets as the dependent variable for the analysis. These absorption spectra were converted into reflection spectra using the Unscrambler software version 9.8 and saved as a separate file then both the absorption and reflection spectra were used for moisture concentration prediction model development. Absorption spectra were obtained from the energy absorbed by the sample at a given wavelength. Measurement of absorption spectra is the widely used technique in chemical analysis. Reflection spectra generally obtained from the light energy that are scattered and reflected by the sample. This reflected light energy has interaction with the sample components to get better information about them. Using data from the calibration dataset, partial least square (PLS) regression analysis was conducted to develop an empirical equation to estimate the pellets MC. Before analyzing the data, spectral data were corrected for baselines to avoid shifts of any variable above the baseline to ensure that all NIR spectra of each moisture contents had the same base line, thereby making it easier to determine differences of data. After base line correction other mathematical pretreatments such as multiple scatter correction (MSC) and derivative functions were applied to the baseline corrected spectral data for better spectral resolution. MSC is applied to base line correct the spectral scattering which is due to the particle size and other physical characteristics of wood pellets. If the analyte moisture content in the pellet is very low, the spectral scattering may cover the spectral information. So, this correction has done on the spectral data to avoid the error in correlation of spectra data with the moisture content, which is the constituent of interest to analyze. MSC would segregate the informative absorbance of the moisture content and the scattering signal in the spectral data and it eliminates the spectral differences in the same batch of pellets. Norris Gap first derivative with gap size of 5 was applied to base line corrected absorption and reflection spectral data with respect to wavelength and derivatives were also calculated. The derivative computation was used to remove any

Table 1. Moisture concentration levels of calibration and validation groups of wood pellets.

\begin{tabular}{cc}
\hline Calibration group MC \% & Validation group MC \% \\
\hline 0.63 & 3.42 \\
3.45 & 6.57 \\
4.47 & 7.76 \\
7.15 & 9.32 \\
7.94 & 12.48 \\
10.31 & \\
14.16 & \\
\hline
\end{tabular}


baseline shifting that may have occurred and resolve overlapping peaks. After applying the derivative treatment, the modified wavelength spectrum showed more details by diminishing the low frequencies and enhancing the high frequencies signals for sample composition concentration. Derivative analysis was limited to first order, because at higher order derivatives, sensitivity may be lost in the characteristic peaks.

PLS analysis was performed on both raw spectral data and derivative data to determine the best calibration model based on Standard Error of Calibration (SEC) and coefficient of multiple determinations $\left(\mathrm{R}^{2}\right)$. SEC is the estimation of calibration procedure and $\mathrm{R}^{2}$ allowed determining the amounts of variation in data predicted by calibration models. The pre-treatment and its PLS model that yielded the best fit were used to predict the pellets moisture concentration from the spectral data of the validation group of pellets. Goodness of fit was evaluated based on the Standard Error of Prediction (SEP) obtained by comparing the reference (standard oven measured) MC values with the predicted moisture concentration. The ratio of the standard deviation of the predicted MC values to the SEP which is residual predictive deviation (RPD) was also used to evaluate the goodness of fit. The RPD values usually range from 1 to 10 . Higher values indicate a stronger calibration model to predict the composition accurately in the unknown samples. RPD values of 1 or less indicate that the model equation predicts the same values in random chances only. RPD values in the range of 3.1 to 4.9 are good for screening purposes and values in the range 5 to 6.4 are good for quality control purposes [16] [17] (Fearn, 2002; Williams, 2001). Bias values, which correspond to the average difference between the standard reference and predicted values, were also considered in model selection.

\section{Results and Discussion}

Strong NIR absorption bands near $1400 \mathrm{~nm}$ - $1440 \mathrm{~nm}$ and $1900 \mathrm{~nm}$ - $1950 \mathrm{~nm}$ have often been applied to a quantitative analysis of water concentration in bio-products. There are changes in the absorption band at the $1400 \mathrm{~nm}$ and $1900 \mathrm{~nm}$ regions caused by the state of water in bio-products [18] (Hans Buning-Pfaue, 2003). Figure 1 shows the NIR absorption spectra of wood pellets at two different moisture concentrations. Peaks represent high absorption of NIR electromagnetic energy. The height and shape of the spectra are dependent on scattering of light. This scatter is affected by difference in sample particle size, reflectance nature of the sample surface and also the spectrum baseline. In general, the spectrum baseline is the dependent character of instrument optics, type of sample cup and distance between the detector and the sample cup. In NIR reflectance spectroscopy, a beam of radiation is impinged on the sample, penetrates a few millimeters, is diffused, and then reflected back to the detector. Since the radiation penetrated and interacted with the sample, it carries absorption information and the representative spectra are returned as NIR absorption curves. The overall spectra of both the varieties show strong absorption bands that differ based on moisture concentration. In general, the region from $700 \mathrm{~nm}$ to $1900 \mathrm{~nm}$ is primarily for first, second and third overtones. Beyond $1900 \mathrm{~nm}$ and up to $2500 \mathrm{~nm}$, a combination of one or more overtone bands accounts for the spectral absorption of water.

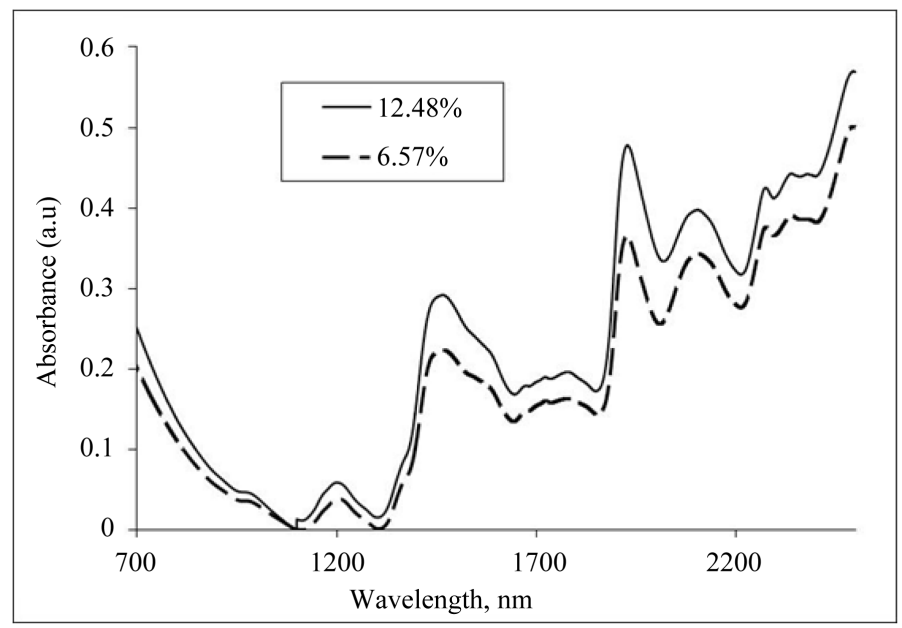

Figure 1. NIR absorption spectra of wood pellets at different moisture concentration. 
Absorption spectral peaks at individual wavelengths have been attributed to various chemical structures other than moisture content such as lignin, cellulose, hemicellulose and extractives. O-H functional groups in water molecules have strong molecular vibration overtones in NIR region from $780 \mathrm{~nm}$ to $2500 \mathrm{~nm}$ and influenced by hydrogen bonding [19] [20] (Osborne et al., 1993; Burns and Ciurczak 2001). Figure 2 shows several spectral peaks for visual observation. The peak at $1200 \mathrm{~nm}$ is assigned to the $2^{\text {nd }}$ overtone of C-H stretching vibration in cellulose [21] (Michell and Schimleck, 1996). The absorption at $1450-1480 \mathrm{~nm}$ range is due to the $1^{\text {st }}$ overtone of O-H stretching vibration in lignin and hemicellulose [22] (Schwanninger et al., 2011). Bands appearing at 1670 - $1830 \mathrm{~nm}$ wavelength range are associated with $1^{\text {st }}$ overtone C-H stretching in cellulose, lignin, hemicellulose and $1^{\text {st }}$ overtone C-H2 stretching in cellulose [22] [23] (Schwanninger et al., 2011; Ali et al., 2001).The peak at $1930 \mathrm{~nm}$ is attributed to a combination of O-H stretching vibration and O-H deformation of water molecules [24] (Sun et al., 2011). Absorption at $2100 \mathrm{~nm}$ is related to a combination of O-H and C-H deformation and O-H stretching vibration in cellulose and xylan [25] (Bassett et al., 1963). Bands at $2275 \mathrm{~nm}-2335 \mathrm{~nm}$ range is correspond to $\mathrm{O}-\mathrm{H}$ stretching vibration and $\mathrm{C}-\mathrm{C}$ stretching in cellulose and $\mathrm{C}-\mathrm{H}$ stretching and $\mathrm{C}-\mathrm{H}$ deformation in cellulose and hemicellulose respectively [22] [23] (Schwanninger et al., 2011; Ali et al., 2001).

Major spectral regions for moisture content prediction in addition to the peaks shown in Figure 1 can be identified exactly using the derivative spectra as shown in Figure 2. It shows the derivative spectra of wood pellets. The first derivative spectra have a trough corresponding to each moisture concentration peak in the original absorption spectra. The absorbance band at the region of $1345 \mathrm{~nm}$ corresponds to the $1^{\text {st }}$ overtone stretching of $\mathrm{O}-\mathrm{H}$ bonds of isolated $\mathrm{OH}$ group in water molecule is not clear in the basic spectrum (Figure 1) and it is shown very clearly in the derivative spectrum (2). Next to this peak a high absorbance value peak is observed at 1450 $\mathrm{nm}$ which is also associated with presence of moisture content. There are several O-H bands in Figure 2 that indicate moisture concentration at $965 \mathrm{~nm}, 1160 \mathrm{~nm}$ and $2035 \mathrm{~nm}$ other than the peaks shown in raw NIR absorption spectra (Figure 1). Moisture content prediction generally based on the presence of $\mathrm{O}-\mathrm{H}$ structure bond in NIR absorption spectra. Peak region around $1940 \mathrm{~nm}$ is due to the stretching and deformation of O-H water bond. Figure 2 shows a slight shift in peak positions at $1450 \mathrm{~nm}$ and $1940 \mathrm{~nm}$. The first derivative curve at different moisture concentration shows slightly different peak positions for each level. The shift is about $10-20$ $\mathrm{nm}$ higher than in the basic spectrum. Since the derivative curves shows modified wavelength spectrum with more details by enhancing the high frequencies, the shifts in peaks are more clearly seen. Water absorption bands are influenced by effects of solutes like ions and organic monomers in water and hydrogen bonds as well, in which the water bonds are strongly associated. The shift of absorption peaks to lower or higher wavelengths are related to the solutes hydration potential and the strength of the hydrogen bonds. In the wood pellets sample there might be more strong hydrogen bonds present, which could influence the NIR absorption. In pure water, hydrogen molecules that attached with O-H groups are considered as free hydrogen, i.e., it does not attach with

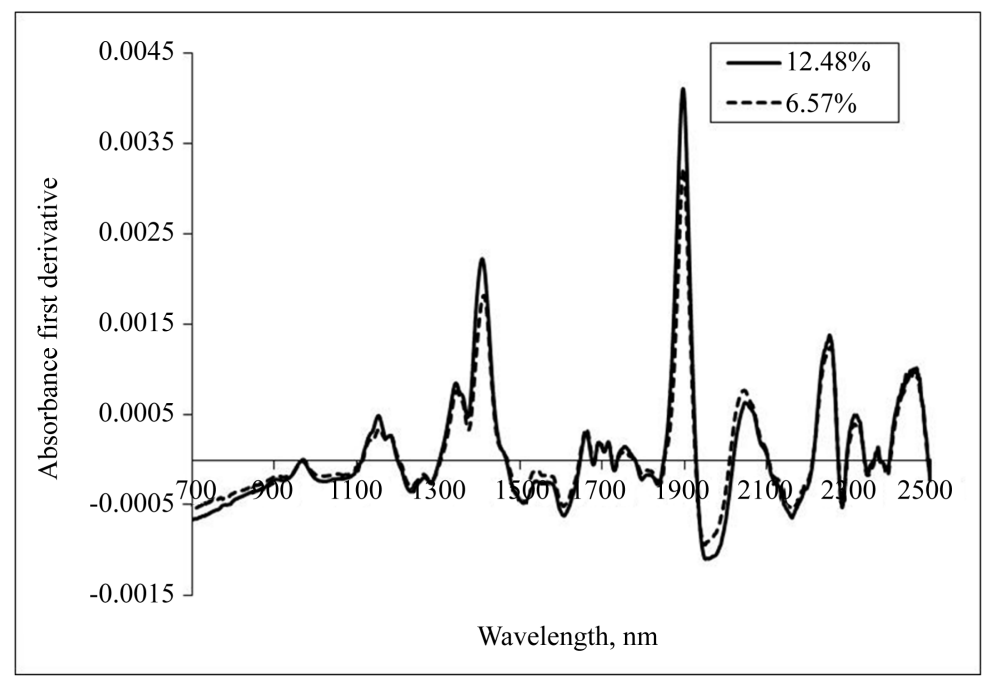

Figure 2. Derivative curves of NIR absorption spectra of wood pellets at different moisture concentration. 
any other foreign molecules. This kind of free hydrogen $\mathrm{O}-\mathrm{H}$ groups give more intensive absorption peaks at lower wavelengths such as for pure water at $975 \mathrm{~nm}$ [26] [27] (Marvin and Singh, 2004; Inoue et al., 1984). But the $\mathrm{O}-\mathrm{H}$ groups with hydrogen molecules that are bonded with carbon, nitrogen or some other molecules as in cellulose, hemicellulose and lignin contents give the water absorption peaks at higher wavelengths.

Figure 3 shows the regression coefficients of the calibration models using absorbance and reflectance spectra with baseline correction, full multiple scatter correction and its $1^{\text {st }}$ derivative developed using PLS. The figure shows that the regression coefficients were obtained from both positive and negative absorption peaks. The peaks ranging between $1400 \mathrm{~nm}-1440 \mathrm{~nm}$ and $1884 \mathrm{~nm}-1930 \mathrm{~nm}$ contributed significantly to the regression coefficients of the calibration equation and these wavelengths are the strong absorption bands of water molecules. $\mathrm{R}^{2}$ and SEC of the calibration regression curves of both absorbance and reflectance spectra with various pre-processing are given in Table 2(a) and Table 2(b).

Table 2(a) and Table 2(b) show the fitness measures of calibration groups of wood pellets obtained using absorbance and reflectance spectra respectively. Calibration set of wood pellets gave $\mathrm{R}^{2}$ of 0.99 for absorbance spectral data treatments and 0.97 for raw data. But reflectance spectra of calibration samples of wood pellets gave the $\mathrm{R}^{2}$ of 0.99 only for reflectance with baseline and full MSC spectra. Also the SEC and RMSEC values of reflectance spectra are higher than the absorbance spectra; however the bias values of reflectance spectra are less than the absorbance spectra except the spectra with baseline correction. All the calibration models equations were used to predict the moisture concentration of wood pellets in the validation sample set. Table 3(a) and Table 3(b) show the fitness measures of validation set after prediction. The predicted RPD values and number of factors obtained for validation set samples are also given in these tables. If the model gives higher RPD and $\mathrm{R}^{2}$ values with less number of factors could be the best model to predict the moisture content.

The best calibration model for wood pellets was found to be the base line and MSC corrected absorption and reflectance spectral data model based on the lowest SEC, RMSEC and bias values (Table 2(b)). Since the $\mathrm{R}^{2}$

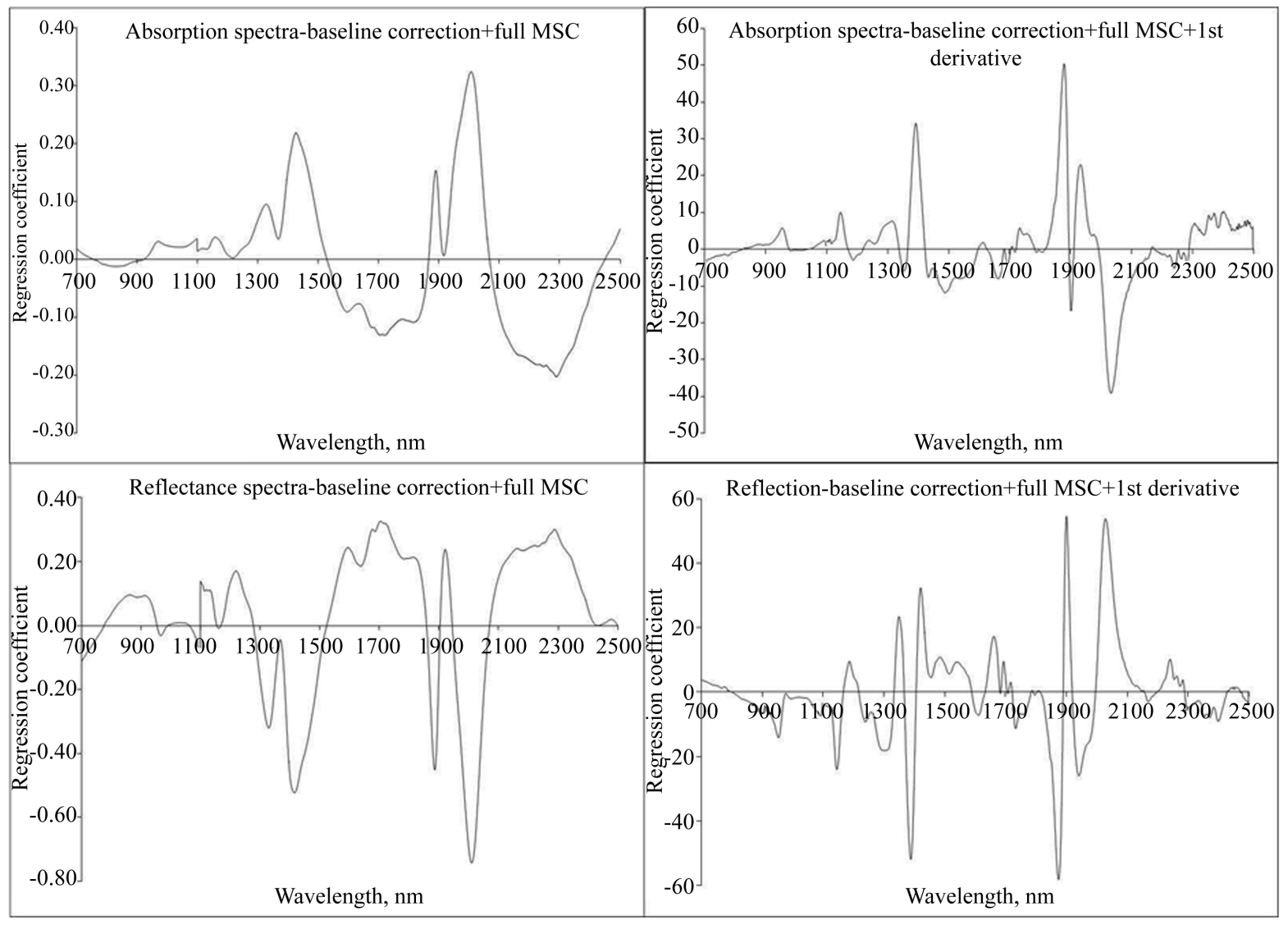

Figure 3. Regression coefficients of absorption and reflectance spectra calibration models developed for wood pellets with different spectral preprocessing. 
Table 2. (a) Fitness measurements of calibration group model developed using absorbance spectra; (b) Fitness measurements of calibration group model developed using reflectance spectra.

(a)

\begin{tabular}{lccccc}
\hline Spectral Treatment & Factors & $\mathrm{R}^{2}$ & SEC & RMSEC & Bias \\
\hline No treatment & 2 & 0.97 & 1.496 & 1.491 & -0.062 \\
Base line correction & 3 & 0.99 & 0.786 & 0.782 & +0.0043 \\
Base line and multiple scatter correction & 3 & 0.99 & 0.675 & 0.672 & $+7.22 \times 10^{-7}$ \\
Base line and multiple scatter corrected with 1 $1^{\text {st }}$ derivative & 3 & 0.99 & 0.831 & 0.827 & -0.00026 \\
\hline
\end{tabular}

(b)

\begin{tabular}{lccccc}
\hline Spectral Treatment & Factors & $\mathrm{R}^{2}$ & SEC & RMSEC & Bias \\
\hline No treatment & 2 & 0.97 & 1.427 & 1.421 & +0.004 \\
Base line correction & 2 & 0.97 & 1.408 & 1.401 & -0.011 \\
Base line and multiple scatter correction & 4 & 0.99 & 0.685 & 0.681 & $+5.878 \times 10^{-7}$ \\
Base line and multiple scatter corrected with $1^{\text {st }}$ derivative & 2 & 0.96 & 0.841 & 0.837 & $-1.01 \times 10^{-7}$ \\
\hline
\end{tabular}

Table 3. (a) Fitness measurements of validation group obtained from absorption spectral model; (b) Fitness measurements of validation group obtained from Reflectance spectral model.

(a)

\begin{tabular}{lccccc}
\hline Spectral Treatment & Factors & $\mathrm{R}^{2}$ & SEP & RMSEP & Bias \\
\hline No treatment & 2 & 0.78 & 1.486 & 1.630 & +0.691 \\
Base line correction & 3 & 0.92 & 0.925 & 0.943 & +0.215 \\
Base line and multiple scatter correction & 3 & 0.94 & 0.742 & 1.025 \\
Base line and multiple scatter corrected with $1^{\text {st }}$ derivative & 3 & 0.93 & 0.892 & 0.905 \\
\hline
\end{tabular}

(b)

\begin{tabular}{|c|c|c|c|c|c|c|}
\hline Spectral Treatment & Factors & $\mathrm{R}^{2}$ & SEP & RMSEP & Bias & RPD \\
\hline No treatment & 2 & 0.76 & 1.535 & 1.537 & +0.190 & 1.83 \\
\hline Base line correction & 2 & 0.82 & 1.530 & 1.523 & +0.098 & 1.88 \\
\hline Base line and multiple scatter correction & 4 & 0.93 & 0.861 & 0.874 & -0.177 & 3.47 \\
\hline Base line and multiple scatter corrected with $1^{\text {st }}$ derivative & 2 & 0.95 & 0.670 & 0.782 & +0.411 & 4.46 \\
\hline
\end{tabular}

values of all the models showed more than 0.95, all were used to predict the moisture content of validation sample wood pellets and their fitness measurement parameters were shown in Table 3(b). Absorbance spectral data models gave RPD of more than 3.0 and SEP of less than 1.0 except the raw data model. Similarly except raw data and the baseline corrected data models of reflectance spectra gave RPD values of more than 3.0 and SEP as well as RMSEP values of less than 1.0. Since the RPD values in the range of 3.1 to 4.9 are good for screening purposes [16] [17] (Fearn, 2002; Williams, 2001), models that show more than 3.0 were considered as good models. Baseline and MSC corrected reflectance spectra with $1^{\text {st }}$ derivative model gave the highest RPD value of 4.46 and $\mathrm{R}^{2}$ of 0.95 , also its SEP (0.670) and RMSEP (0.782) are less than the other models with RPD more than 3.0. Similarly baseline and MSC corrected absorbance spectra model gave RPD of 3.9 with $\mathrm{R}^{2}$ of 0.94 . Thus, these two models were selected as the best model for moisture content prediction of wood pellets. RPD values were used in the best model selection according to the description of RPD and its values as given in Data analysis section above. Generally the height and shape of the spectra are dependent on scattering of light. This scatter is affected by difference in sample particle size, and reflectance nature of the sample surface. Wood pel- 
lets differed in particle size and surface color from each other and it might have changed the spectral baseline. To remove this baseline shifting derivative computation is needed. This could be the reason for high RPD value with less number of factors (2) and goodness of fit using the reflectance spectral derivative calibration model than the absorption spectral model. Graphical comparison between the reference and NIR predicted MC values obtained using the good models regression equations and validation datasets are given in Figure 4. These figures show the individual predicted moisture concentration values obtained from 30 replicates of validation set in the Y-axis and 3 replicates of oven values (ASABE standard method) in the X-axis. Good correlation between the predicted and reference moisture concentration values of wood pellets was achieved. Both NIR absorption and reflection data and their derivatives resulted in $\mathrm{R}^{2}$ in excess of $94 \%$.

\section{Conclusions}

NIR reflectance spectroscopy works well for the analysis of moisture concentration wood pellets rapidly. The calibrations were obtained using partial least square regression analysis. NIR measurement is procedurally very simple, considerably reducing the time required for measurement compared to the standard oven methods. The main reason for conducting this study is to find out more than one NIR wavelength region to determine moisture content of the sample in order to enhance the accuracy in MC determination, unless the commercially available NIR meters which use single wavelength. Using more than one NIR wavelength region determines the moisture content in wide ranges from low to high. Therefore the models shown here for full NIR regions which will help to extract the optimum NIR wavelength regions to build custom NIR moisture meter with improved accuracy level. The use of NIR spectroscopy described in this paper would result in large savings in time, not only for measurement of moisture content, but also for other composition analysis such as cellulose, hemicellulose, lignin and extractives. In general the calorific value of biomass is associated with $\mathrm{C}, \mathrm{H}, \mathrm{O}, \mathrm{N}$ and $\mathrm{S}$ content and their covalent carbon bonds [28].

The prominent peaks appeared in the NIR spectra are not only for moisture content also for spectral signals

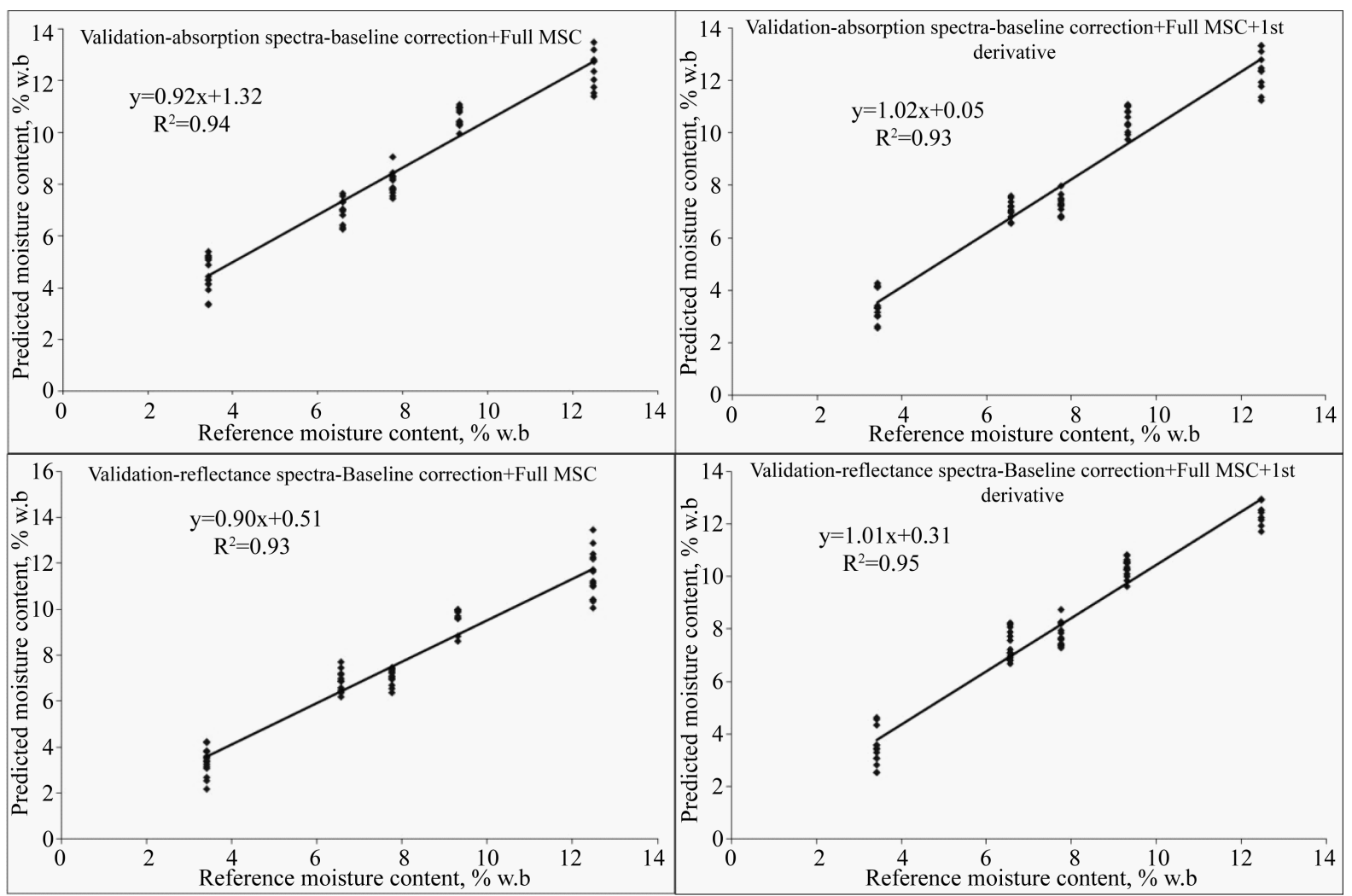

Figure 4. Comparison of NIR predicted moisture content and reference moisture content measured using air oven for wood pellets. 
interaction with covalent carbon bonds such as $\mathrm{C}=\mathrm{C}, \mathrm{C}-\mathrm{H}, \mathrm{C}=\mathrm{O}, \mathrm{C}-\mathrm{O}$ and $\mathrm{N}-\mathrm{H}$ of other compositions. These bonds will provide indirectly the information of C-C bond also. By considering the lowest SEP and the highest RPD values, a model requiring reflectance $1^{\text {st }}$ derivative data with baseline and MSC corrected and absorbance data with baseline and MSC corrected were selected as the preferred calibration for MC prediction of wood pellets. For commercial application of this technique to measure the composition of wood pellets, testing with large number of wood pellets samples from various production regions are required.

\section{References}

[1] Pellet Fuels Institute (PFI) (2011) Pellet Fuels Institute Standard Specification for Residential/Commercial Densified Fuel. Report, Arlington. www.pelletheat.org

[2] ASABE Standards (2008) S358.2: Moisture Measurement-Forages. ASABE, St. Joseph.

[3] Cozzolino, D., Kwiatkowski, M.J., Dambergs, R.G., Cynkar, W.U., Janik, L.J., Skouroumounis, G. and Gishen, M. (2008) Analysis of Elements in Wine Using Near Infrared Spectroscopy and Partial Least Squares Regression. Talanta, 74, 711-716. http://dx.doi.org/10.1016/j.talanta.2007.06.045

[4] Sundaram, J., Kandala, C.V.K., Butts, C.L. and Windham, W.R. (2010) Application of NIR Reflectance Spectroscopy on Determination of Moisture Content of In-Shell Peanuts: A Nondestructive Analysis. Transactions of ASABE, 53, 183-189. http://dx.doi.org/10.13031/2013.29485

[5] Nimaiyar, S., Paulsen, M.R. and Nelson, R.L. (2004) Rapid Analysis of Fatty Acids in Soybeans Using FTNIR, ASABE Paper No. 046118, ASABE, St. Joseph, 15 p.

[6] Pérez-Vich, B., Velasco, L. and Fernández-Martínez, J.M. (1998) Determination of Seed Oil Content and Fatty Acid Composition in Sunflower through the Analysis of Intact Seeds, Husked Seeds, Meal and Oil by Near-Infrared Reflectance Spectroscopy. JAOCS, 75, 547-555. http://dx.doi.org/10.1007/s11746-998-0064-1

[7] Lestander, T.A. and Rhen, C. (2005) Multivariate NIR Spectroscopy Models for Moisture, Ash and Calorific Content in Biofuels Using Bi-Orthogonal Partial Least Squares Regression. Analyst, 130, 1182e9.

[8] Daun, J.K., Clear, K.M. and Williams, P. (1994) Comparison of Three Whole Seed Near Infrared Analyzers for Measuring Quality Components of Canola Seed. Journal of the American Oil Chemists' Society, 71, 1063-1068. http://dx.doi.org/10.1007/BF02675897

[9] Bhatty, R.S. (1991) Measurement of Oil in Whole Flaxseed by Near-Infrared Reflectance Spectroscopy, JAOCS, 68, 34-38. http://dx.doi.org/10.1007/BF02660306

[10] Fagan, C.C., Everard, C.D. and McDonnell, K. (2011) Prediction of Moisture, Calorific Value, Ash and Carbon Content of Two Dedicated Bioenergy Crops Using Near-Infrared Spectroscopy. Bioresource Technology, 102, 5200e6.

[11] Velasco, L. and Becker, H.C. (1998) Analysis of Total Glucosinolate Content and Individual Glucosinolates in Brassica spp. by Near-Infrared Reflectance Spectroscopy. Plant Breeding, 117, 97-102. http://dx.doi.org/10.1111/j.1439-0523.1998.tb01459.x

[12] Lestander, T.A., Johnsson, B. and Grothage, M. (2009) NIR Techniques Create Added Values for the Pellet and Biofuel Industry. Bioresource Technology, 100, 1589-1594. http://dx.doi.org/10.1016/j.biortech.2008.08.001

[13] Yeh, T.F., Yamada, T., Capanema, E., Chang, H.M., Chiang, V. and Kadla, J.F. (2005) Rapid Screening of Wood Chemical Component Variations Using Transmittance Near-Infrared Spectroscopy. Journal of Agricultural and Food Chemistry, 53, 3328-3332. http://dx.doi.org/10.1021/jf0480647

[14] So, C.L. and Eberhardt, T.L. (2010) Chemical and Calorific Characterization of Longleaf Pine Using near Infrared Spectroscopy. Journal of Near Infrared Spectroscopy, 18, 417-423. http://dx.doi.org/10.1255/jnirs.889

[15] Üner, B., Karaman, Ï., Tanriverdi, H. and Özdemir, D. (2011) Determination of Lignin and Extractive Content of Turkish Pine (Pinus brutia Ten.) Trees Using near Infrared Spectroscopy and Multivariate Calibration. Wood Science and Technology, 45, 121-134. http://dx.doi.org/10.1007/s00226-010-0312-z

[16] Fearn, T. (2002) Assessing Calibrations: SEP, RPD, RER and R2. NIR News, 13, 12. http://dx.doi.org/10.1255/nirn.689

[17] Williams, P.C. (2001) Implementation of Near-Infrared Technology. In: Williams, P.C. and Norris, K., Eds., NearInfrared Technology in the Agricultural and Food Industries, 2nd Edition, American Association of Cereal Chemists, St. Paul, 145-169.

[18] Buning-Pfaue, H. (2003) Analysis of Water in Food by Near-Infrared Spectroscopy. Food Chemistry, 82, 107-115. http://dx.doi.org/10.1016/S0308-8146(02)00583-6

[19] Osborne, B.G., Fearn, T. and Hindle, P.H. (1993) Practical NIR Spectroscopy with Applications in Food and Beverage Analysis. Longman Scientific and Technical, Harlow, UK. 
[20] Burns, D.A. and Ciurczak, E.W. (2001) Handbook of Near-Infrared Analysis. Revised and Expanded, 2nd Edition, Marcel Dekker, Inc., New York.

[21] Michell, A.J. and Schimleck, L.R. (1996) NIR Spectroscopy of Woods from Eucalyptus globules. Appita Journal, 49, 23-26.

[22] Schwanninger, M., Rodrigues, J.C. and Fackler, K. (2011) A Review of Band Assignments in Near-Infrared Spectra of Wood and Wood Components. Journal of Near Infrared Spectroscopy, 19, 287-308. http://dx.doi.org/10.1255/jnirs.955

[23] Ali, M., Emsley, A.M., Herman, H. and Heywood, R.J. (2001) Spectroscopic Studies of the Ageing of Cellulosic Paper. Polymer, 42, 2893-2900. http://dx.doi.org/10.1016/S0032-3861(00)00691-1

[24] Sun, B.L., Liu, J.L., Liu, S.J. and Yang, Q. (2011) Application of FT-NIR-DR and FT-IR-ATR Spectroscopy to Estimate the Chemical Composition of Bamboo (Neosinocalamus affinis Keng). Holzforschung, 65, 689-696. http://dx.doi.org/10.1515/hf.2011.075

[25] Bassett, K.H., Liang, C.Y. and Marchessault, R.H. (1963) Infrared Spectrum of Crystalline Polysaccharides. IX. The Near-Infrared Spectrum of Cellulose. Journal of Polymer Science Part A, 1, 1687-1692. http://dx.doi.org/10.1002/pol.1963.100010520

[26] Marvin, R.P. and Singh, M. (2004) Calibration of a Near-Infrared Transmission Grain Analyzer for Extractable Starch in Maize. Biosystems Engineering, 89, 79-83. http://dx.doi.org/10.1016/j.biosystemseng.2004.05.009

[27] Inoue, A., Kojima, K., Taniguchi, Y. and Suzuki, K. (1984) Near-Infrared Spectra of Water and Aqueous Electrolyte Solutions at High Pressures. Journal of Solution Chemistry, 13, 811-823. http://dx.doi.org/10.1007/BF00647696

[28] Gillon, D., Henando, C., Valette, J.C. and Joffre, I. (1997) Fast Estimation of the Calorific Values of Forest Fuels by Near-Infrared Reflectance Spectroscopy. Canadian Journal of Forest Research, 27, 760-765. http://dx.doi.org/10.1139/x97-021 